\title{
Recruitment and Selection Practices in Small and Medium Enterprises: Perspectives from Ghana
}

\author{
Dan Ofori (Corresponding author) \\ Department of Organisation and Human Resource Management \\ University of Ghana Business School \\ P. O. Box LG 78, Legon, Accra- Ghana \\ Tel: +233-244-548-501Ｅmail: dofori@ug.edu.gh \\ Majoreen Aryeetey \\ Department of Organisation and Human Resource Management \\ University of Ghana Business School \\ P. O. Box LG 78, Legon, Accra- Ghana \\ Email: maryeetey@ug.edu.gh
}

Received: July 19, 2011 Accepted: August 9, 2011 doi:10.5430/ijba.v2n3p45

\begin{abstract}
Effective recruitment and selection practices are key factors to the entry point of human resources in any organization and they also tend to determine the success and sustainability of SMEs. This present study sought to identify the skills and competences required of graduates by SMEs, and the graduates selection and recruitment practices of SMEs. A questionnaire survey was chosen as the most appropriate design for this investigation, with purposive sampling being used to select respondents ranged from company top management. The data was analysed using SPSS. The results suggest that a majority of SMEs do recruit graduates but do not retain them beyond three years. Respondents identified information technology as the most important skill they require of graduates; followed by numerical skills, written communication skills, oral communication skills, confidence and self discipline. The findings will enhance a realistic recruitment and selection interface between graduate jobseekers and SME recruiters in Ghana.
\end{abstract}

Keywords: Recruitment and Selection, Small and Medium Enterprises, Human Resources, Ghana

\section{Introduction and Problem Statement}

Small and medium enterprises (SMEs) represent about 92\% of Ghanaian businesses and contribute about $70 \%$ to the nation's GDP and more than 80 percent to employment (Abor and Adjasi, 2007). Small and medium-sized businesses [SMEs] contribute significantly to the growth of economies. According to Chapman (1998) small firms (employing 50 or less), account for $99 \%$ of enterprises in the UK. In Ghana, SMEs have been identified as the catalyst for the country's economic growth as they are a major source of income and employment (Mensah, 2004). In recent times, Ghanaian SMEs appear to have made significant gains in selling their products and services in the larger West African market (Puplampu, 2005). Additionally, more and more SMEs have been established and aimed at foreign markets (Hinson, 2007).

To Ongori (2010), "recruitment and selection practices are the key factors to the entry point of human resources to any organization which also tends to determine the success and sustainability of SME's”. Human resource practitioners and academics worldwide hold the belief that, survival, growth and development of an organisation grossly depend on an effective and efficient culture of recruitment, selection and placement of people endowed with broader and deeper range of core competencies, preferred attitudes, knowledge, skills and experiences. The ultimate goal of recruitment, selection and placement of people is to bring to bear on organisations, preferred attitudes, behavior and culture to elicit better performance irrespective of one's ability or otherwise (Encyclopedia of international business and management, 1996). 
An exploratory study by Puplampu (2005) found that human skills and competencies are required for the effective management of SMEs. One major finding from Puplampu (2005) was that some SMEs considered themselves as unsuccessful because of poor technical capacity, human resource problems and performance. These SMEs believe that the possession of certain skills and competencies are required for success in the regional and international markets. Professional skills were by far the greatest need alongside others like human, technical and academic capacity skills. These professional skills relate to team and marketing skills, strategic planning, leadership and managerial skills among many others. The least important skill according to the survey is academic capacity which refers to educational qualifications and time spent at school. It is therefore necessary to consider how SMEs can better position themselves internally in terms of their skills and competencies, corporate structures and leader foci (style, background, strategy and vision) in order to enter and successfully operate in the regional and international market place (Puplampu, 2005).

It is now well established that one of the factors which inhibit small business growth is the shortage of management competence within the firm (Daniels et al., 1993). Puplampu (2005) asserts that lack of managerial know-how places significant constraints on SME development whilst Monsted (1989) also concluded that the majority of entrepreneurs have little or no managerial experience prior to setting up their business and no formal management training or qualifications. Therefore to develop and improve the level of managerial competencies an SME has three possible options: develop the managerial competence of the owner; employ consultants when management problems arise; and recruit another employee to perform a managerial role. However, recruiting people who are wrong for the organisation can produce long-term negative effects like high training costs, increased labour turnover and generally increased costs for the organisation. At worst, the organisation could possibly fail to achieve its objectives thereby losing its competitive edge and its share of the market (Armstrong, 2009).

Large organisations no longer are able to absorb the significant number of university and other tertiary graduates entering the labour market and this has forced the small and medium sized businesses sector into the limelight. There is growth of employment within the small and medium sized (SME) sector, thus it comes as no surprise that the SME sector has therefore been highlighted as having the potential to offer graduates the opportunity of their first "trip" along their career journeys (Stewart and Knowles, 2000). It is estimated that SMEs employ 22\% of the adult population in developing countries (Daniels, 1994). In Ghana data from the Registrar General's office indicates that about $90 \%$ of registered companies are SMEs (SECO-IFC, 2007). However, although SMEs act as a good stepping stone for some graduates, recent studies have shown that a majority of those graduates end up in different jobs after three years; (DFEE, 1996; Harvey, et al., 1997; Williams and Owen, 1997) based on this and the growing significance of SMEs as potential and actual employers of graduate students at some point in their careers, this present study will seek to consider whether: SMEs offer graduate employment opportunities; what jobs SMEs will recruit graduates for; which skills and competences SMEs look for during a graduate recruitment and selection process; and whether recruited graduates are retained after employment.

\subsection{Research Objectives}

This paper aims to highlight the skills and competencies SME employers require of graduates in the recruitment and selection process. It specifically aims to:

- Assess which jobs SMEs offer as employment opportunities;

- Identify and rank skills and competencies SMEs look for in a graduate recruitment and selection process;

- Identify factors which inhibit graduate recruitment in SMEs

- $\quad$ Ascertain whether graduates recruited are retained.

\subsection{Research Questions}

Based on the foregoing research objectives, the study seeks answers to the following questions:

- Do SMEs recruit tertiary graduates?

- What types of jobs are offered to graduates?

- What kind of skills and competencies do SMEs look for when recruiting and selecting graduates?

- Are graduates retained after employment?

\subsection{Research Hypothesis}

The following hypothesis will be tested in addition to the above research questions. 
- SMEs that recruit graduates with the required skills and competences will outperform their counterparts who do not recruit skilled graduates.

\subsection{Significance of the Study}

The study seeks to contribute to existing knowledge and explore links between higher education and SME employers in Ghana. Research into the graduate recruitment and selection practices of SME employers and the skills and competencies required from graduates will firstly assist training and education authorities to better equip graduates with the skills required in the job market. It would also promote the integration of education at tertiary institutions and workplace learning. Findings from the study would benefit graduates, as they would learn the skills required by employers to be able to perform better, especially in SMEs.

\section{Literature Review}

\subsection{Definitions and Concepts of Small and Medium Enterprises (SMEs)}

There is no single, uniformly acceptable definition of a small firm (Storey, 1994). Kayanula and Quartey (2000) state that firms differ in their levels of capitalisation, sales and employment. The Bolton Committee (1971), formulated an “economic and statistical” definition whereby firms in manufacturing, construction and mining were defined in terms of numbers of employees (in which case 200 or less qualified the firm to be a small firm), those in retail, services, wholesale etc were defined in terms of monetary turnover (in which case the range is 50,000- 200,000 British Pounds to be designated small). Firms in motor trades sector are designated small if they have a turnover of 100,000 British Pounds or less. According to Storey (1994:13) the European Commission (EC) coined the term "Small and Medium Enterprises" (SME): made up of three components: firms with 0-9 employees- micro enterprises; 10-99 employees- small enterprises; 100-499 employees- medium enterprises. In effect, the EC definitions are based solely on employment rather than a multiplicity of criteria. The Ghana Statistical Service (GSS) considers firms with less than 10 employees as Small Scale Enterprises and their counterparts with more than 10 employees as Medium and Large - Sized Enterprises (Kayanula and Quartey, 2000).

However the National Board of Small Scale Industries (NBSSI) applies both the 'fixed asset and number of employees' criteria. It defines a small scale enterprise as one with not more than 9 workers with plant and machinery (excluding land, building and vehicles) not exceeding 1000 Cedis (Kayanula and Quartey, 2000). The above shows that there is a problem when it comes to defining SMEs but whatever the case may be, they contribute significantly to the development of countries especially the developing ones like Ghana. As noted by Kayanula and Quartey (2000), 'the dynamic role of SMEs in developing countries as engines through which the growth objectives of developing countries can be achieved has long been recognised'. SMEs are noted to employ $22 \%$ of the adult population in developing countries and more specifically, about $15.5 \%$ of the Ghanaian labour force.

\subsection{The Role of SMEs and Constraints to Their Development}

Small and Medium Enterprises are especially effective job creators and have a reputation for providing income and training opportunities as well as important basic services for disadvantaged people (Altenburg et. al, 2006). Many of such firms are owned and operated by entrepreneurs and their families - manager/owner (Chell, 1999; Moran, 1999). According to Puplampu, (2005) the Ghanaian situation is not much different. Buame (2000) also highlights that SMEs account for some 50\% of GDP in Ghana. Kayanula and Quartey (1998) also indicated in their study that the SME sector's output as a percentage of GDP accounted for 6\% of GDP. The above highlights the growth of the sector in recent times.

Forstater et al (2002) have argued that SMEs offer a unique opportunity for developing countries to grow. Anheier \& Seibel, 1987; Liedholm and Mead, 1987; Schmitz, 1995; have all suggested that SMEs are more labour intensive than larger firms and therefore, have lower capital costs associated with job creation. They also improve the efficiency of domestic markets and make productive use of scarce resources, thus, facilitating long term economic growth (Quartey, 2000). However, SMEs face a variety of constraints such as difficulty of absorbing large fixed costs, the absence of economies of scale and scope in key factors of production, and their higher unit costs of production (Puplampu, 2005 citing Schmitz, 1982; Steel and Webster, 1990). Other constraints include input constraints, finances and cash flow (Aryeetey et al., 1994), domestic demand (Daniels and Ngwira, 1993), access to international markets and regulatory constraints (Aryeetey et al, 1994). According to Puplampu (2005), lack of managerial know-how also places significant constraints on SME development.

\subsection{Essence of Recruitment and Selection Practices}

Griffen (2006) explained management as a process of managing the resources of the organisation. These resources he mentioned are financial, physical, information and human. Mathis and Jackson (2010) admitted that, of all resources 
available to organisations, humans are the glue that hold or bind the other resources. This implies that, without the right personnel, SMEs will be found wanting in terms of performance. Since SMEs are labour intensive (Anheier \& Seibel, 1987; Liedholm and Mead, 1987; Schmitz, 1995), recruitment and good selection practices are inevitable.

For Bratton and Gold (2007), recruitment and selection practices involve two interrelated processes. Recruitment is the process of generating a pool of capable people to apply for employment to an organisation whiles selection is the process by which specific instruments are employed to choose from a pool of applicants' most suitable for the job taking into consideration, management goals and legal requirements. Recruitment therefore provides the organisation with a pool of potentially qualified candidates from which selection can be made to fill job openings. Recruitment and selection are therefore a crucial part of organisational success. Spencer (2004) mentioned that effective recruitment and selection are strategically important to any firm. Recruiting and selecting the wrong candidates can have extensive negative cost implications, while effective processes can contribute to a reduction in turnover and therefore increase in productivity.

Most businesses would like to benefit from an influx of talent, enthusiasm and fresh ideas. However it comes with an acceptable cost. Armstrong (2009) suggests that the overall aim of the recruitment and selection process should be to obtain at minimum cost the number and quality of employees required to satisfy the human resource needs of the organisation. He asserts that the three stages of recruitment and selection are; defining requirements (preparing job descriptions and specifications, deciding terms and conditions of employment), attracting candidates (reviewing and evaluating alternative sources of applicants, inside and outside the organisation) and selecting candidates (sifting applications, interviewing, testing, assessing candidates, assessment centres, offering employment, obtaining references; preparing contracts of employment).

Sources of recruitment are either internal or external but an organisation's choice will depend on the human resources needs and objectives with each of them having their merits and demerits. Cascio (2010) identifies that in deciding where, when and how to implement recruitment activities, initial consideration should be given to a company's current employees, especially for filling jobs above the entry level. According to Cascio (2010), if external recruitment efforts are undertaken without considering the desires, capabilities and potential of present employees, both short and long run costs may be incurred. Internal sources could be by job posting, referrals etc (Desslar, 2008; Shillingi, 2010).

According to Armstrong (2009) and Dessler (2008), the employee selection process usually takes place in the following order:

There is a preliminary interview which is used to eliminate those candidates who do not meet the minimum eligibility criteria identified by the organisation. Candidates who are successful in the first stage are required to complete application blanks which detail the candidate's age, qualification, experience etc. Written tests which could comprise of aptitude, intelligence, personality etc test are also conducted during the selection process. These tests are usually seen to be objective and unbiased. Successful candidates then go through employment interviews where there is an interaction between the interviewer and interviewee which has the aim of getting candidates who are suitable for the job. In order to decrease chances of absenteeism and ensure a proper fit with the job, medical tests are conducted to ensure physical fitness of the potential employee. After proper reference checks, the candidate is then finally appointed by the provision of a formal appointment letter.

\subsection{Empirical Evidence of Graduate Recruitment in SMEs}

Small employers tend to recruit as required. They do not have formal graduate schemes and are not tied to any set of recruitment or to a fixed recruitment programme, so vacancies may occur at any time of the year. Small companies may also not have a formal graduate recruitment brochure or application form. Interviews are likely to be informal and staff may not be trained in interview skills, so candidates will need to make sure that they bring out their strongest selling points and ask lots of questions (Kent Careers, 2008). Common to the findings of Williams and Owen (1997), Stewart and Knowles (2000), through interviews, established that recruitment activities undertaken by SMEs generally relied on newspaper advertisements to generate applicants. None of the three SMEs interviewed, however used application forms in the recruitment process.

With respect to the selection process, all the SMEs rely heavily upon the interview, which concurs with Gabb (1997) who refers to employers still considering the interview as an essential part of the selection process. Harvey et al (1997) report that a variety of ways of actually selecting graduate employees are adopted, the common practice being the use of application forms and interviews with larger recruiters often combining these methods with assessment centres and various forms of tests. However, they comment that for smaller companies, using sophisticated assessment centres is not a viable approach to recruiting graduates. 
According to Batram et al (1995), the recruitment and selection practices used by small organisations are different from those applied by large firms. Unlike large firms, small businesses tended to use more informal and unstructured mechanisms. Employers of small businesses also consider applicants personality characteristics such as honesty, integrity and interest in the job more importantly than ability, aptitude or attainment.

Holden et. al., (2002) investigated the importance of a university qualification in job selection with 18,561 SMEs. They found that 77 percent of the sample believed that 'attitude and character' were important factors for recruitment followed by experience (64 percent) and an industry related course (41 percent). However, only 9 percent of the sample believed that a university qualification was an important requirement for employee selection. Graduates in the eyes of Employers (2002) observed in their survey of 104 companies that over 70 percent believed that degrees were devalued as a means of measuring employability and 51 percent felt that graduates were not necessarily better equipped for the workplace when compared to non graduates of the same age. SMEs have also tended to claim that it is expensive to employ and train graduates particularly given the risk that they will leave after training to go to a bigger firm (Beer and Salt, 2004). Pittaway and Thedam (2004) found that micro businesses did not believe their business to be appropriate for graduates as they could not utilize graduate skills. Although some evidence suggests that SMEs tend to have a negative perception toward graduate employment, examples abound of valuable and beneficial contributions of graduates to their firms (Stewart and Knowles 2002).

A series of qualitative interviews were conducted with SME managers in the North East of UK (Johnson, 1993) and findings were that, SME managers saw graduates as a product of the academic world. The academic world was seen as sheltered, insular, protective and divorced from reality, useless and impractical compared to the business world which was perceived as practical, money, time and results oriented. Over 70 percent of the interviewees expressed serious doubts of the ability of graduates to make the cultural leap from the academic world to the business world. The interviewees perceived graduates as arrogant, elitist and unwilling to join and communicate with others well educated than them. This negative perception of graduates made the interviewees seriously reluctant to recruit into their firms.

In a survey of 1033 SMEs, Williams and Owen (1997) observed that the majority of the sample perceived graduates as unlikely to stay in long term employment, lacked relevant work experience and wanted a salary that was far too high for their job role. In spite of these findings, graduates are perceived positively with their ability to communicate ideas, the creative skills they possessed and their IT skills. Williams and Owen (1997) further observed that, in principle a majority of SMEs were opposed to the idea of employing graduates. This, the authors suggest will be because employers are not graduates themselves hence may feel threatened and uncomfortable at the notion of employing graduates. However, employers who are graduates themselves may be more likely to recruit graduates into their organisation.

William and Owen (1997) further highlight a number of important findings with respect to recruitment and selection of graduates within SMEs:

- The intake for graduates seemed more likely to occur in SMEs where a graduate has responsibility for recruitment.

- The main perceived benefits of recruiting graduates cited were being good with clients, having well developed management skills bringing new ideas

- There was also a general perception that a graduate’s additional knowledge and enhanced skills would be advantageous.

- 15 percent had recruited ex-placement or vacation student to their full time staff, following graduation. Such methods of recruitment were considered to be valuable in terms of providing an effective and economic way of recruiting future graduate employees. Other most popular methods of graduate recruitment cited were news papers advertisements, universities or personal contacts.

\subsection{Graduate Contribution to SMEs}

The Association of Graduate Recruiters (1995) states that SMEs will need to understand the benefits graduates can bring so that the likelihood of future graduates entering employment within the SME sector is realized. As advanced earlier by Williams and Owen (1997), 'graduates are said to benefit the companies they work for by being good with clients, having well developed management skills and bringing new ideas'. Stewart and Knowles (2000) also posit that "from the interviews conducted, benefits were cited for example, Company Y perceived that a fresh graduate would bring 'new ideas' into the company that has got quite a number of old heads". Company X considered that recruiting more graduates into the company would result in having 'better skills and trained managers' which would 'enable the company to grow'. 


\subsection{Graduate Underrepresentation in SMEs}

SMEs have tended to claim that it is expensive to employ and train graduates particularly given the risk that they will leave after training to a bigger firm (Beer and Salt, 2004). There are however external barriers to consider that may contribute to the under representation of graduates in SME's. Several researches conducted showed that, there is a growing body of evidence that suggests that large companies often pay significantly higher salaries when compared with SMEs for the same caliber of graduates (Kullberg and Burren, 1996; Miller and Mulvey, 1996). This finding was supported by Bedfield (1999) who observed that the average salary for graduates in companies with over five hundred employees was thirty six percent higher than those in organisations with less than twenty five employees.

A further barrier involves work bargaining and fringe benefits in SMEs compared with large companies. Research by Bedfield (1999) found that fringe benefits (ranging from merit related pay to pension schemes) are significantly more common in large firms. Nabi (2003) argues that SME managers may not consider their businesses to have any job opportunities at graduate level. This perception amongst managers of SMEs is likely to prevent such organisations from recruiting graduates because they do not see any worth, value or benefit for their firm by employing them (Holden and Jameson, 2002). In this same regard, graduates may be recruited into low skill jobs within SMEs, sometimes with little or no reference to their qualifications, as the graduate may choose underemployment rather than unemployment because of lack of traditional 'graduate level' opportunities (Small Business Service, 2002). The above could explain why graduates are more likely to seek employment in large companies rather than SMEs.

\section{Methodology}

As noted by Delport (2002), questionnaires or survey designs are one of the data collection methods used when working from a qualitative perspective. Creswell (1994) also maintains that the main aim of a qualitative study is to make an enquiry into a human or social problem, test a theory composed of variables, measure it with numbers and analyse it statistically. The study therefore employed a survey and interview approach. A detailed questionnaire was designed using a cross-sectional approach in which primary data was sought from the sample SMEs. The questionnaire included both open and closed ended questions with variables to be measured. Purposive sampling technique was used to generate a sample of 30 Ghanaian growth SMEs form the data base of the Association of Ghanaian Industries (AGI) because they are more likely to employ graduates than non-growth companies (Kerlinger and Lee, 2000). Although two respondents each were targeted, only 30 were received representing a response rate of $60 \%$. The targeted respondents were company owner-managers in the Ga-East and Ga-West Districts of the Greater-Accra region of Ghana, encompassing the capital city.

A two-section questionnaire was designed and piloted in ten SMEs. Questions covered the research objectives: recruitment of graduates in the SME; skills and competencies important for graduate recruitment and selection in SMEs; factors inhibiting graduate recruitment in SMEs and graduate retention in SMEs. Data collected for objectives I and 3 was analysed using the statistical package for the social sciences (SPSS) with results expressed in descriptive statistics such as percentages and frequencies. Objective 2, which is to identify and rank the skills and competencies SMEs look for in graduate recruitment and selection was analysed using Kendall's Coefficient of Concordance $(W)$ given as:

$W=\left[\frac{\sum T-\left(\sum T\right)^{2} / n}{m^{2}\left(n^{2}-1\right) / 12}\right]$

$W$ is an index that measures the ratio of the observed variance of the sum of ranks to the maximum possible variance of the sum of ranks. The idea behind this index is to find the sum of ranks for each skill and competence being ranked and then to examine the variability of the sums. If the rankings are in perfect agreement, the variability among the sums will be at a maximum.

In the study $m$ is the graduates to be recruited by the SMEs whilst $n$ represents the skills and competencies which need to be possessed by the graduates, categorised under academic and transferable skills as: Numeric skills ; Information technology skills; Written communication; Oral communication; Self discipline; Confidence; Leadership skills; Mature attitude ; Interpersonal and teamwork; Positive Work Ethics; Time management; Negotiation skills; Decision making skills; Innovation; Problem Solving, etc. 


\section{Data Analysis and Results}

Descriptive and inferential statistics were used in analyzing the responses from the questionnaire. Percentages formed the descriptive instrument while Kendall's Coefficient of Concordance was the inferential statistical instrument used.

\subsection{Discussion of Empirical Findings}

Results in Table 1 indicate the category of SMEs involved in the study.

$<$ Table 1 about here>

Thirteen of the respondent firms representing $43.3 \%$ were micro enterprises; a further $4.3 \%$ were small scale enterprises while the least numbers of SMEs (4) representing $13.4 \%$ were medium sized enterprises. The SMEs are selected from industries ranging from manufacturing to service delivery. Specifically, of the 30 SMEs, 10 (33.3\%) were into manufacturing, 5 (16.6\%), Agro processing, 9 (30.0\%) in service delivery, 3 (10.0\%) in trading retail while only 1 (3.3\%) were engaged in imports of goods. However, all the 30 companies were registered under the Ghana Companies Code. This is an indication of good business management and knowledge of entrepreneurship by the owners and managers of the companies involved in the survey.

\subsection{Companies Recruiting Graduates}

According to Ongori (2010), "recruitment and selection practices are the key factors to the entry point of human resources to any organization which also tends to determine the success and sustainability of SME's". In relation to the above, the study sought to find out if SMEs recruit graduates since they are skilled labour. Results of the survey indicated that some SMEs recruit graduates while others do not and Table 2 provides the summary below. Out of the 30 SMEs, 93.3\% indicated that they did recruit graduates while only $6.7 \%$ indicated that they do not recruit graduates. This confirms the findings by Cushlow (1999), and Stewart and Knowles, (2000) that some SMEs recruit graduates. However, it is in sharp contrast to Pittaway and Thedam's (2004) findings which found that micro businesses did not believe their business to be appropriate for graduates as they could not utilize graduate skills.

Specifically, 2 SMEs (6.6\%) each indicated that they recruit the following number of graduates annually 3, 4, 6 and 10 respectively. Only 1 SME each indicated that they recruit 8 and 50 graduates annually in expectation of various structural expansions in the business. This confirms studies undertaken by authors like Stewards and Knowles (2000) and, Pittaway and Thedham (2005) that SMEs recruit few numbers of graduates as compared to larger firms. These results vindicate studies conducted elsewhere but it is noteworthy that one SME reported a figure of 50 graduates recruited annually.

$<$ Table 2 about here $>$

\subsection{Jobs for which SMEs Recruit Graduates}

The study further sought to ascertain for which jobs SMEs recruit graduates. In Table 3 the results presented shows that of the total of 59 responses obtained with regards to the jobs $8.4 \%$ mentioned marketing, managerial and secretarial jobs. Fifteen respondents (25.4\%) mentioned accounting, while $12(20.3 \%)$ mentioned administrative jobs. One respondent each (1.7\%) mentioned the following jobs respectively; customer service, pharmacy, manufacturing, sales representative, computing, community task work, software development, poultry technician, architecture and field surveyors whilst two respondents (3.3\%) mentioned business development services.

\section{$<$ Table 3 about here $>$}

\subsection{Identification and Ranking of Skills and Competencies Important for Graduate Recruitment and Selection in SMEs}

$<$ Table 4 about here $>$

There are various skills and competencies that SMEs deem important for graduate recruitment and selection. To rank these skills and competencies in order of the most pressing to the least pressing, the Kendall's Coefficient of Concordance ( $W$ ) analysis was employed. The results are presented in Table 4 below. It can be observed that there is $40.3 \%$ agreement between the rankings of the skills and competencies that SMEs consider important before recruiting graduates. Collectively the SMEs expressed information technology with the least mean rank of (4.85\%), as the most pressing competency and skill needed whilst innovation on the part of the graduate with a mean rank of (12.27) was the least pressing competency required. This might be because most owner/managers being entrepreneurial tend to be innovative and creative, thus generating most of the ideas needed in managing their businesses and thus needing less of that skill. The 14 other competencies and skills with their mean ranks are indicated as follows.

Numerical skills (5.25); written communication (5.33); oral communication (5.73); confidence (6.55); self discipline (6.68), mature attitude (8.20); interpersonal and teamwork (8.38); leadership skills (8.53); time management (9.30); positive work ethics (9.50); decision making (10.65); problem solving (11.70); negotiating skills (12.07) and others (11.77). 


\subsection{Hypothesis and Test for W (Competencies and Skills)}

Ho: There is no agreement in the rankings of the competencies and skills required by SMEs before recruiting graduates.

Hi: There is an agreement in the rankings of the competencies and skills required by SMEs before recruiting graduates.

In testing for the level of significance for the hypothesis set for the rankings, a chi-square value of (193.291) which is statistically significant at $10 \%$ was obtained as provided in Table 5 below.

\section{$<$ Table 5 about here $>$}

Hence the null hypothesis (Ho) is rejected and the alternate hypothesis (Hi) is accepted. There is therefore agreement between the skills and competencies that SMEs require from graduates before they are recruited.

\subsection{Factors Inhibiting Graduate Recruitment into SMEs}

The study further investigated the factors that inhibit graduate recruitment into SMEs in Ghana. Three respondents each representing (6.5\%) mentioned cost of maintaining graduates in SMEs as expensive; also some graduates have poor managerial skills, and SMEs not being able to offer high job earnings as compared to larger firms. The inability of SMEs to offer high job earnings was confirmed as several studies conducted showed that, there is a growing body of evidence that suggests that large companies often pay significantly higher salaries when compared with SMEs for the same calibre of graduates (Kullberg and Burren, 1996; Miller and Mulvey, 1996). It was also reiterated by Bedfield (1999) who observed that the average salary for graduates in companies with over five hundred employees was thirty six percent higher than those in organisations with less than twenty five employees hence this reason could account for reasons inhibiting SMEs from employing graduates.

One respondent each representing (2.2\%) expressed the following as inhibiting factors of graduate recruitment into SMEs; some graduates are not hardworking; some graduates have poor relationships with subordinates and management and some employers especially non graduates feel intimidated by the graduates. This happens to be another confirmation by Williams and Owen (1997) who suggested that because employers are not graduates themselves, they may feel threatened and uncomfortable at the notion of employing graduates.

$<$ Table 6 about here $>$

Training of old staff to do the job is more preferred; graduates are not flexible and cannot adapt to change; graduates do not consult SMEs for employment but rather prefer to send their applications to large organizations. SMEs cannot afford to pay graduates so they go for senior high school leavers and train them; Graduates are of no use in areas of decision taking because the owner or manager takes all the decisions.

Two respondents each representing (4.3\%) expressed the following; SMEs are not financially sound to be able to recruit more graduates and meet their demands and some graduates find it difficult to apply book knowledge to practical situations. This other factor was long established by Johnson (1993) that SME managers saw graduates as a product of the academic world and this world was seen as sheltered, insular, protective and divorced from reality. This therefore implies that SME managers in the north east of UK and Ghana have similar views concerning graduate employment.

Other inhibiting factors mentioned are; the nature of the job does not require graduate recruitment and lack of experience on the part of the graduates. $4.3 \%$ also did not provide any responses, 6 respondents (13\%) expressed that the remuneration provided by SMEs is low.

Thus, these results make the idea of most graduate entrants having serious skills gap, lack of initiative and weak interpersonal skills the most frequented (17.4\%) factor which inhibits graduate recruitment into SMEs, followed by the low remuneration provided by SMEs.

\subsection{Graduate Retention in SMEs}

The study further sought to ascertain the number of graduates that are retained by SMEs and the period of retention. The results showed that out of the thirty respondents, only 8 (26.6\%) retained the graduates recruited.

Of that number, 2 firms (6.6\%) each indicated that they retain the graduates for 6 months and 10 years respectively; 2 firms (6.6\%) each also indicated that they each are able to retain the graduates for 2 years and 3 years respectively. Therefore out of the 30 firms, 24 representing (80\%) indicated that they are not able to retain the graduates recruited. These results are significant because as noted by Williams and Owen (1997), and Stewart and Knowles (2000), 'graduates are said to benefit the companies they work for by being good with clients, having well developed management skills and bringing new ideas'. Therefore if Ghanaian SMEs do not retain the vast majority of graduates they recruit, they would undoubtedly lose the benefits and value that might have accrued to their firms. Interestingly, finding from the interviews conducted seemed to support the assertions of Williams and Owen (1997) and Stewart and 
Knowles (2000). These are reflected in some of the comments of top management members: Company Y perceived that a fresh graduate would bring 'new ideas' into the company that has got quite a number of old heads". Company X considered that recruiting more graduates into the company would result in having 'better skills and trained managers' which would 'enable the company to grow'.

Clearly therefore, top managers recognize the potential plus points of graduate recruitment and retention in their firms. Why then do they let graduates leave? Is it solely due to the inability of firms to hold on to graduates or do the reasons lie with the graduates? In seeking to answer these questions, the study probed further for the reasons for low graduate retention among the SMEs.

\subsection{Reasons for Low Graduate Retention}

Out of the total of 30 responses, 2 respondents each (6.3\%) mentioned that the conditions of service and company policies are not good enough; there is no job security in SMEs; and graduates use their first jobs with the SMEs as stepping stones to greener pastures. A respondent each representing (3.1\%) expressed respectively, that the graduates cannot cope with the demands of the jobs; the relationship between the boss and the employers is often poor so the graduates leave; and SMEs do not offer career paths and job packages that would entice graduates to stay. Seven respondents representing (21.8\%) opined that most graduates are not satisfied with their remuneration so they search for jobs while working with the SMEs and they finally leave.

$<$ Table 7 about here $>$

\section{Conclusions}

On the basis of the foregoing, the following conclusions may be drawn from the study:

- Most Ghanaian SMEs indicated that they do recruit graduates into their companies. This seems to reflect the results of a study by Williams and Owen (1997) who similarly found that $34 \%$ of the 1,033 companies surveyed had recruited at least one recent or experienced graduate in the preceding five years. However, responses from some respondent companies also show that Ghanaian SMEs have no career progression or path and hence no obvious “organization-defined” career paths for graduates to respond positively towards.

- Also, Ghanaian SMEs do recruit graduates for a wide range of jobs, thus from administrative type jobs such as secretaries and administrative staff, customer service, training and so on to more technical jobs such as: computing (IT), architecture, finance, accounting and the like.

- The study also indicated that transferable skills and qualities do play an important role in the potential employability of graduates with small and medium sized companies. Results from the Kendall's Coefficient of Concordance $(W)$ analysis confirm the above stated facts. Information Technology skills ranked $\left(1^{\text {st }}\right)$, written communication skills $\left(3^{\text {rd }}\right)$, oral communication skills $\left(4^{\text {th }}\right)$, leadership skills $\left(9^{\text {th }}\right)$, and so on. These findings are in conformity with Puplampu's (2005) study which showed that human skills and competencies are required for the effective management of SMEs. A major finding from Puplampu (2005) was that some SMEs considered themselves as not successful because of poor technical capacity and human resource problems. These SMEs believed that the possession of certain skills and competencies are required for success in the regional and international markets.

- In general, studies have shown that employers particularly emphasize communication skills as one of the most important skills required of graduates (Harvey et. al. 1997; William and Owen, 1997; Stewart and Knowles, 2000). This much was reflected in the research findings, with both verbal and written communication skills receiving very high ratings from respondents, irrespective of whether or not they currently recruit graduates. Similarly, Harvey et al (1997) refer to SMEs valuing team working skills, which also concurred with our research findings.

- However, the ranking of information technology skills in first (1st) position contradicts the Graduate Employment and Training Report cited in Stewart and Knowles (2000), which found that numerical and IT skills can hardly be described as 'key' to employers' skills wish lists'. This may be explained by the fact that in a highly developed country setting with high literacy and IT skills, almost all graduates would be adept at ICT skills. This can be contrasted with a developing country like Ghana where ICT tools are not widely diffused so possession of IT skills can still be seen as a novelty.

- With regards to graduate retention after employment, the results of the study would seem to suggest that SMEs interviewed did not have such strong convictions regarding the long- term retention of graduates. For example, an SME in manufacturing expected to retain graduates for approximately two years and acknowledged that it was 
difficult for SMEs to fulfil a graduate's long term aspirations due to the apparent lack of career progression. Another firm, an estate developer suggested that perhaps fresh graduates would use the SME work experience as a means of 'reality testing' and work towards achieving a stable career which was expected to be with other, larger organisations.

\section{Recommendations}

The study makes recommendations for three key players; potential graduates, SMEs and the Higher Education Institutions in Ghana as follows:

\subsection{Potential Graduates}

Individuals have varied reasons for choosing to continue their formal education but common to all must be the expectation that their degree and development during their courses will enhance employability in the future. This study has shown that many employers, especially, SMEs are seeking 'well rounded graduates', who have a degree and are also equipped with and aware of the range of skills and qualities that can be transferred to the workplace.

However, it was observed that the commonest occurring factor that was cited as inhibiting graduate recruitment into SMEs, was, 'most graduate entrants have serious skills gap, initiative and have weak interpersonal skills'. Thus, individuals should not only concentrate on attaining academic qualifications but must also learn to develop the skills and qualities that future employers from all sizes of organisations will require in the workplace and expect graduates to demonstrate within the context of the work situation.

\subsection{Small Businesses}

It has been highlighted that the SME sector has experienced growth in terms of creating new job opportunities for graduates, yet penetration of graduates into this sector seems to be slow. SMEs could therefore focus on formalising and documenting their recruitment and selection practices. SMEs should also consider planning graduate recruitment around the academic year. A study by William and Owen (1997), found a great deal of support for their suggestion that Higher Education Institutions (HEIs) and SMEs should develop partnerships to facilitate both the needs of small businesses and the needs of graduates. SMEs should encourage recruitment on internship basis to help graduates acquaint themselves with organizational skills and ethics.

\subsection{Higher Education Institutions}

Higher Education Institutions (HEIs) can take up the role of assisting students to develop skills and transfer their learning and development to the world of work. Higher education institutions can play a role in introducing students to a full range of employment opportunities that exist upon graduation. Such opportunities include the SME sector. Hence a better flow of information about SMEs to graduates might encourage more of them to consider careers in small firms.

Finally, closer partnerships between the HEIs and SMEs may also assist in addressing some of the challenges that exist in generating and realising employment opportunities for graduates within this sector. The AGR (1995) refers to SMEs possessing a lack of awareness of what both universities and graduates have to offer. Perhaps the utilization of undergraduates via work experience opportunities incorporated within the curriculum could be a means of addressing this concern.

\section{Suggestions for Future Research}

Future research might expand the sample size as SMEs abound in other regions in Ghana. Graduates could also be sampled for confirmation of assertions by SMEs managers.

\section{References}

Abor J. and Adjasi, C. (2007). Corporate Governance and the Small and Medium Enterprises Sector: Theory and Implications, Corporate Governance, Vol. 7(2), pp. 111-122. doi:10.1108/14720700710739769 http://dx.doi.org/10.1108/14720700710739769

Altenburg, T. and Eckhardt, U. (2006). "Productivity enhancement and equitable development: Challenges for SME development”, UNIDO Research Programme, Vienna, 2006.

Armstrong, M. (2009). Human Resource Management Practice. Eleventh Edition London: Kogan Page Ltd.

Association of Graduate Recruiters (1995). Skills for Graduates in the $21^{\text {st }}$ Century, Cambridge, October.

Bartram, D. (1995). The recruitment and selection of young people by small businesses. Journal of Occupational and Organisational Psychology 
Belfield, C. R. (1999). the Behaviour of graduates in the SME Labour Market: Evidence and Perceptions. Small Business Economics. 12, 249-259, doi:10.1023/A:1008011303353 http://dx.doi.org/10.1023/A:1008011303353

Bratton, J. and Gold, J. (2007) Human Resource Management: Theory and Practice $2^{\text {nd }}$ Edition London: MacMillan

Careers Advice and Employment Service (CAES) (1999). “The Changing Nature of Graduate Careers”, The Nottingham Trent University, Nottingham.

Cascio, W. (2009). Managing Human Resources: Productivity, Quality of Work Life, Profits (11 ${ }^{\text {th }}$ edition), New York: McGraw-Hill.

Chapman M. (1998). Small firms: overlooked or misunderstood? Reflections on an emerging field in work/organisational psychology in The Occupational Psychologist, 34

Cushlow, F. (1999) North West Small and Medium Sized Enterprise Employees Needs and Expectations of Higher Education- A holistic approach to Labour market and Intelligence.

Daniels, L and Ngwira A. (1993), 'Results of a Nation-wide Survey on Micro, Small and Medium Enterprises in Malawi', GEMINI Technical Report No. 53. New York: PACT Publications.

Department for Education and Employment (DFEE) (1996), Labour Market Skills and Trends 1996/97, DFEE, London.

Dessler, G. (2008). Human Resource Management (11 $1^{\text {th }}$ ed), New Jersey: Prentice Hall, pp 56.

Encyclopaedia of International Business and Management (1996), London: Routledge.

Graduates in the eyes of employers (2002). The Guardian in partnership with the Association of Graduate Recruiters (AGR).

Griffin W. R (2006). Management (8 ${ }^{\text {th }}$ ed) New York: Houghton Mifflin Company

Harvey, L., Moon, S. and Geall, V. (1997). Graduates’ Work: Organisational Change and Students’ Attributes Centre for Research into Quality, the University of Central England, Birmingham.

Holden, R. \& Jameson, S. (2002) Employing graduates in SMEs: towards a research agenda. Journal of Small Business and Enterprise Development. 9, 3, 271-84. doi:10.1108/14626000210438599, http://dx.doi.org/10.1108/14626000210438599

Johnson, S. (1993). Graduate retention and the regional economy. Entrepreneurship and the Regional Econom Development. 5.doi:10.1080/08985629300000007, http://dx.doi.org/10.1080/08985629300000007

Kalleberg, A. L. \& M. E. van Buren (1996). Is Bigger Better? Explaining the Relationship between Organisation Size and Job Rewards. American Sociological Review. 61, 47-66. doi:10.2307/2096406 http://dx.doi.org/10.2307/2096406

Kauda, J. (2005): “Internationalisation and Enterprise Development in Ghana” (Adonis \& Abbey Publishers Ltd.)

Kerlinger, F. N. \& Lee, H. B. (2000). Foundations of behavioural Research (4 ${ }^{\text {th }}$ edition). Orlando: Harcourt College Publishers.

Liedholm C and Mead D (1987). 'Small Scale Industries in Developing Countries: Empirical Evidence and Policy Implications', International Development Paper No. 9, Dept of Agricultural Economics, Michigan State University, East Lansing, MI, USA.

Malkin, J., Allen, A., Hambley, L. and Scott, F. (1997). "Rational career planning”, Perspectives on Career Planning, Occasional Papers in Careers Guidance No. 1, Institute of Careers Guidance.

Mathis R.L and Jackson J.H (2010). Human Resource Management, $13^{\text {th }}$ Edition, US: South-Western Learning.

Mensah S (2004). ‘A review of Small and Medium Scale Enterprises financing Schemes in Ghana'. A document presented at the UNIDO Regional Workshop of Financing SMEs. Accra.

Miller, P. \& C. Mulvey (1996). Unions, Firm Size and Wages. The Economic Record 72, $138-153$. doi:10.1111/j.1475-4932.1996.tb00948.x http://dx.doi.org/10.1111/j.14754932.1996.tb00948.x

Nabi, G. R. (2003). Graduate employment and underemployment: opportunity for skill use and career experiences amongst recent business graduates. Education and Training. 7, 371-382. doi:10.1108/00400910310499947, http://dx.doi.org/10.1108/00400910310499947

Nabi, G. R. and Bagley, D. (1998), “Graduate’s perceptions of transferable personal skills and future career preparation in the UK”, Career Development International, Vol. 3 No. 1, pp. 31-9. doi:10.1108/13620439810368619, http://dx.doi.org/10.1108/13620439810368619(Permanent URL) 
Ongori, H. (2010). Recruitment and Selection Practices in SMEs: Empirical Evidence from a Developing Country Perspective. Advances in Management, vol. 3, issue 2 pp 52-58

Saffu, K., H. Walker and R. Hinson (2007). “An empirical study of perceived strategic value and adoption construct: The Ghanaian Case” Management Decision vol. 45 No. 7, 2007 pp. 1083-1101, (Emerald Group Publishing Ltd.), doi:10.1108/00251740710773925

Schmitz H (1995). "Collective Efficiency: Growth path for small scale industry”, The Journal of development studies, Vol. 31 No. 4 pp. 529-566.doi:10.1080/00220389508422377, http://dx.doi.org/10.1080/00220389508422377

Shillingi, G. (2010). Personnel Selection, Journal of Occupational and Organisational Psychology 74(4), 441

Spencer, J.D. (2004). Fundamentals of Staff Development, University of New England

Steele, W. F. \& Webster, L. (1990). “Ghana’s small enterprise sector survey of adjustment response and constraint”, Industry Series paper 41, World Bank, Industry and Energy Department, Washington DC.

Stewart, J \& Knowles, V. (1999). “The changing nature of graduate careers”, Career Development International, Vol. 4 No.7, pp. 370-83. doi:10.1108/13620439910295754, http://dx.doi.org/10.1108/13620439910295754

Stewart, J \& Knowles, V. (2000a). Graduate recruitment and selection practices in small businesses”, Career Development International, Vol. 5 No.1, pp. 21-38. doi:10.1108/13620430010309332, http://dx.doi.org/10.1108/13620430010309332

Stewart, J \& Knowles, V. (2000b). “Graduate recruitment and selection: implications for HE, graduates and small business recruiters”, Career Development International, Vol. 5 No. 2, pp. 65-80. doi:10.1108/13620430010318909, http://dx.doi.org/10.1108/13620430010318909

Storey, D. (1994). Understanding the Small Business Sector, Routledge: London.

Terre Blanche, M. \& Durrheim, K. (2004). Research in Practice. Applied methods for the behavioural Sciences. University of Cape Town Press: Cape Town.

The Noticeboard: Paper for Small and Medium Scale Enterprises, No. 13, Dilton Consult, Osu.

Williams, H. and Owen, G. (1997). Recruitment and Utilisation of Graduates by Small and Medium Sized Enterprises, Department for Education \& Employment (DFEE), Research Report NO. 29, October. London.

Wynarczyk P, Watson R, Storey D. J., Short H \& Keasey K (1993). The Managerial Labour Market in Small \& Medium Sized Enterprises, Routledge: London.

http://www.citeman.com/why-organizations-prefer internal-sources-accessed 10/02/2008

http://mycpf.cpf.gov.sg/CPF/my-cpf/Hire-Empl.htm-accessed 13/02/2008

www.citeman.com/recruitment-is-distinct-from-employment-accessed 10/02/2008 
Table 1. Category of Companies

Source: Field data, 2010

\begin{tabular}{|c|c|c|}
\hline Category & Frequency & Percentage \\
\hline Micro & 13 & 43.3 \\
\hline Small Scale & 13 & 43.3 \\
& & \\
\hline Medium & 4 & 13.4 \\
\hline Total & 30 & 100 \\
\hline
\end{tabular}

Table 2. Graduates Recruited Annually

\begin{tabular}{|c|c|c|}
\hline No. Recruitment Annually & No. of SMEs & $\%$ \\
\hline 1 & 6 & 20 \\
\hline 2 & 10 & 33.3 \\
\hline 3 & 2 & 6.6 \\
\hline 4 & 2 & 6.6 \\
\hline 5 & 4 & 13.3 \\
\hline 6 & 2 & 6.6 \\
\hline 8 & 1 & 3.3 \\
\hline 10 & 2 & 6.6 \\
\hline 50 & 1 & 3.3 \\
\hline Total & 30 & 100 \\
\hline
\end{tabular}

Source: Field data, 2010

Table 3. Jobs for which SMEs Recruit Graduates

\begin{tabular}{|c|c|c|}
\hline Jobs & Frequency & $\%$ \\
\hline Marketing & 5 & 8.4 \\
\hline Accounting & 15 & 25.4 \\
\hline Managerial & 5 & 8.4 \\
\hline Finance & 4 & 6.7 \\
\hline Administration & 12 & 20.3 \\
\hline Customer Service & 1 & 1.7 \\
\hline Pharmacy & 1 & 1.7 \\
\hline Manufacturing & 1 & 1.7 \\
\hline Sales Representative & 1 & 1.7 \\
\hline Computing & 1 & 1.7 \\
\hline Research & 1 & 1.7 \\
\hline Community Task work & 1 & 1.7 \\
\hline Secretarial & 5 & 8.4 \\
\hline Software development & 1 & 1.7 \\
\hline Poultry technician & 1 & 1.7 \\
\hline Architecture & 1 & 1.7 \\
\hline Field surveyor & 1 & 1.7 \\
\hline Business development & 2 & 3.3 \\
\hline Total & 59 & 100 \\
\hline
\end{tabular}

Source: Field data, 2010 
Table 4. Rankings of Competencies and Skills

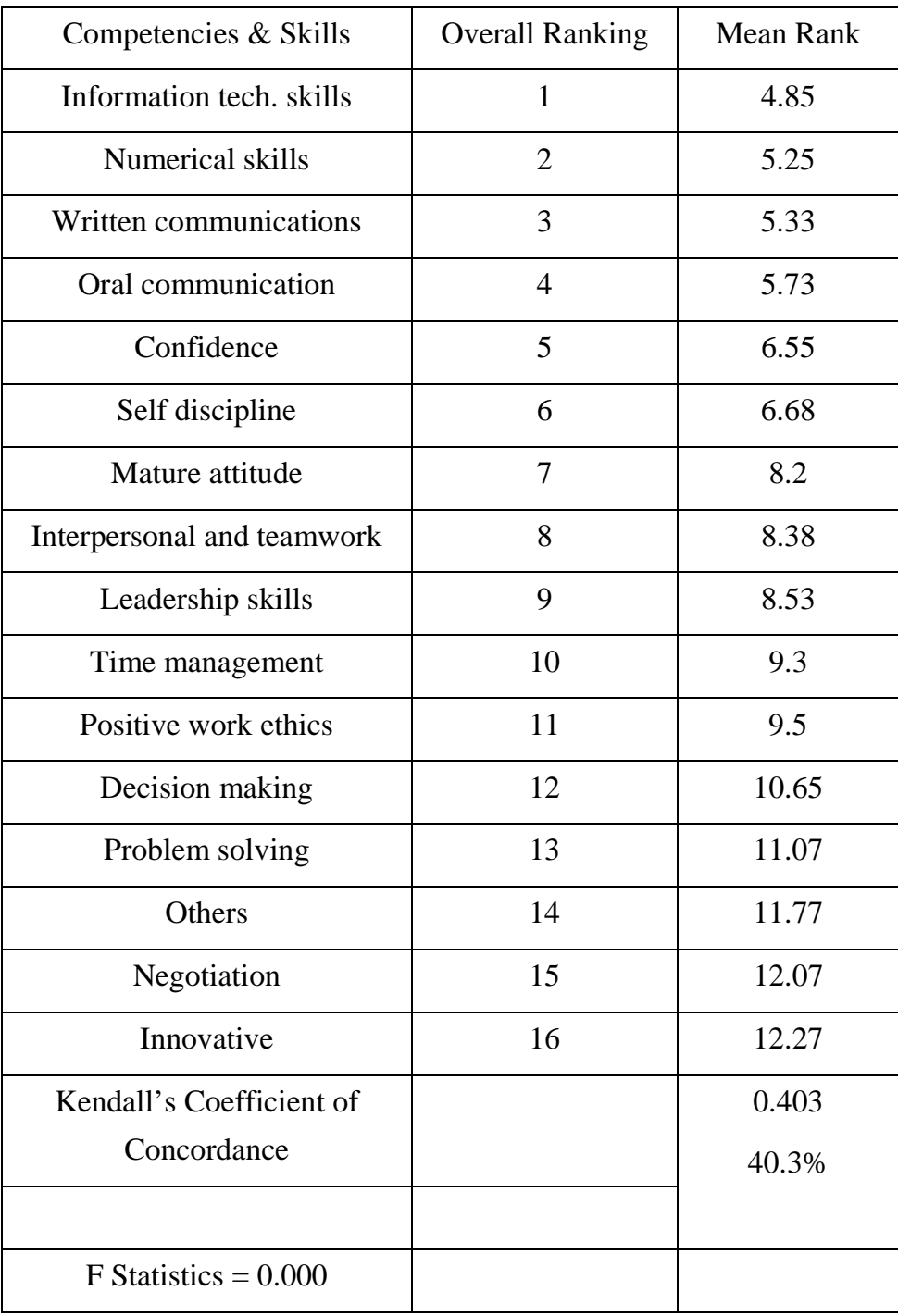

Source: field data, 2010

Table 5. Test Statistics

\begin{tabular}{|c|c|}
\hline $\mathrm{N}$ & 30 \\
\hline Kendall's Wa & 0.403 \\
\hline Chi-Square & 193.291 \\
\hline $\mathrm{df}$ & 16 \\
\hline Asymp.Sig & 0 \\
\hline
\end{tabular}


Table 6. Factors Inhibiting Graduate Recruitment into SMEs

\begin{tabular}{|c|c|c|}
\hline Factors & Frequency & $\%$ \\
\hline Most graduate entrants have serious skills gap, initiative and have weak interpersonal skills & 8 & 17.4 \\
\hline The remuneration provided by SMEs is low & 6 & 13 \\
\hline Poor conditions of service provided by SMEs & 4 & 8.7 \\
\hline Some graduates have poor managerial skills & 3 & 6.5 \\
\hline Cost of maintaining graduates is expensive & 3 & 6.5 \\
\hline SMEs cannot afford high job earnings as compared to larger firm & 3 & 6.5 \\
\hline SMEs are not financially sound to be able to recruit more graduates and meet their demands & 2 & 4.3 \\
\hline Some graduates find it difficult to apply book knowledge to practical situations & 2 & 4.3 \\
\hline Lack of experience on part of graduates & 2 & 4.3 \\
\hline The nature of the job does not require graduate recruitment & 2 & 4.3 \\
\hline Some graduates are not hardworking & 1 & 2.2 \\
\hline Some graduates have poor relationship with subordinates and management & 1 & 2.2 \\
\hline Graduates are not flexible and cannot adapt to change & 1 & 2.2 \\
\hline $\begin{array}{l}\text { Graduates do not consult SMEs for employment; they only send their applications to large } \\
\text { organisations. }\end{array}$ & 1 & 2.2 \\
\hline SMEs have no recruitment system in place & 1 & 2.2 \\
\hline Some SMEs do not have large enough premises to recruit graduates into & 1 & 2.2 \\
\hline Some SMEs cannot afford to pay graduates so they go for SSS leavers and train them & 1 & 2.2 \\
\hline $\begin{array}{l}\text { Graduates are of no use in areas of decision taking because the owner or manager takes all } \\
\text { the decisions }\end{array}$ & 1 & 2.2 \\
\hline Some employers especially non graduates feel intimidated by the graduates & 1 & 2.2 \\
\hline Training of old staff to do the job is more preferred & 1 & 2.2 \\
\hline Total & 46 & 100 \\
\hline
\end{tabular}

Source: Field data, 2010 
Table 7. Reasons for Low Graduate Retention

\begin{tabular}{|l|c|c|}
\hline \multicolumn{1}{|c|}{ Reasons } & Frequency & $\%$ \\
\hline No response & 10 & 31.2 \\
\hline $\begin{array}{l}\text { Most graduates are not satisfied with the salary so they search for jobs while working with } \\
\text { the SMEs and they finally leave }\end{array}$ & 21.8 \\
\hline $\begin{array}{l}\text { Most of the graduates leave after acquiring training so they can bargain at larger } \\
\text { organisations for better remuneration with their acquired knowledge }\end{array}$ & 3 & 3.4 \\
\hline They lack confidence to work & 3 & 9.4 \\
\hline $\begin{array}{l}\text { Most of the graduates leave after acquiring training so they can bargain at larger } \\
\text { organisations for better remuneration with their acquired knowledge }\end{array}$ & 2 & 6.3 \\
\hline The conditions of service and company policies are not good & 6.3 \\
\hline There is no job security & 2 & 6.3 \\
\hline Graduates use their first jobs with the SMEs as stepping stones to greener pastures & 3 \\
\hline They cannot cope with the demands of the job & 3.1 \\
\hline $\begin{array}{l}\text { The relationship between the boss and the employers is often so poor so the graduate } \\
\text { leaves }\end{array}$ & 3.1 \\
\hline SMEs do not offer career paths and Job packages that would entice graduates to stay & 1 & 3.1 \\
\hline Total & 300 \\
\hline
\end{tabular}

Source: Field data, 2010 